\title{
Exploring inequalities in access to care and the provision of choice to women seeking breast reconstruction surgery: a qualitative study
}

\author{
S Potter ${ }^{\star}, 1,2, \mathrm{~N} \mathrm{Mills}^{1}$, S Cawthorn ${ }^{3}, \mathrm{~S} \mathrm{Wilson}^{4}$ and J Blazeby ${ }^{1,2}$ \\ ${ }^{1}$ Centre for Surgical Research, School of Social and Community Medicine, University of Bristol, Canynge Hall, 39 Whatley Road, \\ Bristol BS8 2PS, UK; ${ }^{2}$ Division of Surgery, Head and Neck, University Hospitals Bristol NHS Foundation Trust, Marlborough Street, \\ Bristol BS2 8HW, UK; ${ }^{3}$ Breast Care Centre, North Bristol NHS Trust, Southmead Hospital, Bristol BS10 5NB, UK and ${ }^{4}$ Department \\ of Plastic Surgery, Frenchay Hospital, Bristol BS16 1LE, UK
}

Background: Breast reconstruction (BR) may improve psychosocial and cosmetic outcomes after mastectomy for breast cancer but currently, few women opt for surgery. Reasons for this are unclear. The aim of this qualitative study was to explore access to care and the provision of procedure choice to women seeking reconstructive surgery.

Methods: Semi-structured interviews with a purposive sample of patients who had undergone BR and professionals providing specialist care explored participants' experiences of information provision before BR. Interviews were transcribed verbatim and analysed using the constant comparative technique of grounded theory. Sampling, data collection and analysis were performed concurrently and iteratively until data saturation was achieved.

Results: Both patients and professionals expressed concerns about the provision of adequate procedure choice and access to care. Lack of information and/or time, involvement in decision making and issues relating to the evolution and organisation of reconstructive services, emerged as potential explanations for the inequalities seen. Interventions to improve cross-speciality collaboration were proposed to address these issues.

Conclusion: Inequalities in the provision of choice in BR exist, which may be explained by a lack of integration between surgical specialities. Pathway restructuring, service reorganisation and standardisation of training may enhance cross-speciality collaboration and improve the patient experience.

Whether to undergo breast reconstruction (BR) surgery after mastectomy for breast cancer is a decision faced by $\sim 14000$ women every year in the United Kingdom (Jeevan et al, 2008). The routine offer of immediate breast reconstruction (IBR), unless contraindicated for medical reasons, was introduced as the standard of care in 2002, and the past decade has seen the emergence of a new general surgical subspeciality, oncoplastic breast surgery, to meet this demand and supplement the limited reconstructive services hitherto solely provided by plastic surgeons (Baum, 2003; Skillman and Humzah, 2003; Malycha et al, 2008). The appointment of specifically trained oncoplastic breast surgeons (OPBS) at district general hospitals has enhanced the provision of reconstructive care in two ways: first, by offering a range of reconstructive procedures, often implant-based and pedicled-flap reconstructions locally to women diagnosed with breast cancer; second, by acting as an effective and appropriate referral route 
should more complex microvascular free-flap reconstruction be considered necessary or desirable. This effectively created a hub and spoke' model of reconstructive services with plastic surgical centres as the central 'hub' and the OBPS as the 'spokes'.

Despite these moves to improve access to reconstructive care and the provision of choice for patients with breast cancer, the recent National Mastectomy and Breast Reconstruction Audit has shown that the uptake of IBR nationally remains low. Less than half of all women requiring a mastectomy are currently offered surgery and only one in five elect to undergo the procedure (Jeevan et al, 2009). Furthermore, the uptake and pattern of reconstructive surgery performed varies markedly (from 9 to $43 \%$ ) across regional cancer networks. Reasons for these disparities have been explored and although variability in patient preferences may contribute (Jeevan et al, 2010a), patient comorbidity and concerns regarding adjuvant therapy may predominantly explain the limited offer of IBR (Jeevan et al, 2009). Whether patients are offered 'all appropriate breast reconstruction options... irrespective of whether they are all available locally' (National Institute Of Clinical Excellence, 2009), in line with the national guidance, however, is less well-established and surgeons' rationale for procedure choice has yet to be explored. Patients' perceptions of the provision of choice, by contrast, have been investigated. Questionnaire data from the National Mastectomy and Breast Reconstruction Audit suggests that although over $70 \%$ of women undergoing immediate reconstruction were initially satisfied with the options they were given regarding the types of surgery (Jeevan et al, 2011), only $65 \%$ were satisfied with the choices they received 18 months after reconstruction (Jeevan et al, 2011). This raises concerns about the provision of choice to patients seeking BR and suggests that further investigation is needed.

Qualitative research, which aims to understand 'why' and 'how' rather than 'how many', is a useful tool for exploring sensitive or political issues in-depth. Interviews can generate greater insights into participants' perceptions of care and allow issues of importance to be explored in more detail and understood (Pope and Mays, 1995; Malterud, 2001; Kuper et al, 2008). It may also generate an understanding of how and why problems exist in different contexts (Britten, 1995). We therefore aimed to use qualitative methods to explore patients' and health professionals' experiences and perceptions of the provision of choice in reconstructive surgery to determine whether women seeking BR are offered an appropriate choice and if barriers to the provision of choice exist, to understand how these may be overcome.

\section{METHODS}

Study design and setting. The data for this paper come from the multimethod BRAVE (Breast Reconstruction and Valid Evidence) study, which used systematic reviews (Potter et al, 2011a, b) and qualitative methods to investigate the feasibility of randomised clinical trials in BR (Potter, 2011; Potter et al, 2013). The study received full ethical approval (LREC reference number 09/ $\mathrm{H} 0102 / 50)$.

\section{Recruitment}

Health professionals. The BRAVE study explored the feasibility of randomised clinical trials in $\mathrm{BR}$ and thus the initial sampling strategy targeted opinion leaders in breast and plastic surgery practicing at high-volume centres with advanced training fellowships. Maximum variation sampling subsequently aimed to identify individuals based on speciality, gender, experience and centre of practice (with or without on-site plastic surgical services). As the study progressed, theoretical sampling was used to identify professionals whose views were hypothesised to prove or disprove emergent theory. Participants were also asked to recommend other health professionals who may provide interesting or additional insights into the phenomenon under study.

Patients. Patients referred from a number of peripheral hospitals in south-west England were recruited from the breast and plastic surgical units of a large regional referral centre based at a teaching hospital in a large university city. The rate of immediate reconstruction in this region is similar to the national average (Jeevan et al, 2010a) with $\sim 55 \%$ of the women opting surgery and $\sim 22 \%$ electing to undergo reconstruction (Jeevan et al, 2009). The centre is served by three consultant OPBS regularly performing implant-based and pedicled-flap reconstructions and three plastic surgeons with a special interest in reconstructive breast surgery providing a regional free-flap service. The centre also benefits from clinical nurse specialists (CNS) in both breast cancer and BR. It is a high-volume BR centre, performing $\sim 250$ primary BRs each year.

Potential participants were identified from the operating diaries of the six consultant surgeons and through liaison with the CNS. Purposive sampling was initially used to ensure maximum variation with regard to participant age, type and timing of surgery. As the study progressed, theoretical sampling was used to identify participants whose views may enhance or disprove emerging theory.

An invitation letter, patient information sheet and consent form were sent to each potential participant. Women who chose to participate were asked to return a completed reply slip with contact details and were contacted by telephone to identify a suitable time for an interview.

Data collection. Semi-structured qualitative interviews were conducted by a medically qualified researcher (SP) using topic guides developed from a review of the literature (Appendix 1). The topic guides explored participants' perceptions of access to care and the provision of choice, and were iteratively modified as research progressed to allow emerging themes to be explored. Interviews were undertaken at a time and place convenient to the study participant and written consent was obtained before each interview. Reflective notes were made as soon as possible after the interviews to capture any nonverbal cues and the researcher's feelings about the interview. All interviews were digitally audiorecorded, transcribed in full and the accuracy of the transcripts checked against the original recording. Each participant was assigned a study pseudonym to protect confidentiality. Patient and professional interviews were conducted concurrently to allow emergent themes to be explored between the groups.

Analysis. Analysis of both patient and HP interviews was initiated soon after data collection commenced and was an ongoing and iterative process that informed further sampling and data collection. The purpose of the analysis was to develop theoretical explanations for participants' opinions, behaviours and decisions. Interviews were analysed inductively in small batches by reading the transcripts of the audio-recordings thoroughly and then systematically assigning labels (codes) that captured the meaning of the words to segments of text. Emerging codes were then grouped into similar concepts or themes and explored in subsequent interviews. Further analysis employed the constant comparison technique of grounded theory (Glaser and Strauss, 1967; Pope et al, 2000) in which data were examined for differences and similarities within themes, taking into account the context in which these themes were mentioned. This ensured that findings were systematically compared and grounded in the data. Early codes were subsequently modified, refined or new codes added as interviews and analysis progressed. Individuals exhibiting contrasting attitudes ('negative cases') were studied in detail to understand reasons underlying such contrasts and to gain a deeper understanding of the data and findings. New data were compared with findings from previous interviews to identify similarities and 
differences in participants' experiences. Further sampling was then undertaken to explore emergent themes. Sampling, data collection and analysis were undertaken concurrently and iteratively until data saturation was achieved and no new themes emerged from the data.

Analysis was undertaken by SP with the support of an experienced social scientist (NM). A sample of the transcripts was independently recoded to check the coding structure (NM) and the plausibility of data interpretation was verified by discussion with members of the research team (NM and JMB).

\section{RESULTS}

Participant demographics. Sixty-two interviews were undertaken with 35 health professionals (including two interviews with pairs of CNS) and 31 patients. The characteristics of the participants are summarised in Tables 1 and 2.

Professionals. Interviews were undertaken with OPBS $(n=11)$, plastic surgeons $(n=11)$, CNSs $(n=11)$ and clinical psychologists $(n=2)$ providing specialist reconstructive services at 15 centres throughout the United Kingdom (Table 1). Surgeons had a median of 13 years specialist experience (range 0-29) and performed a median of 30-40 primary reconstructions per year (range 0-290) (Table 1).

Patients. Thirty-one women with a median age of 51 years (range 31-72 years) who had undergone a range of reconstructive procedures (expander-implant reconstruction $n=11$; latissimus dorsi (LD) flap reconstruction $n=10$; DIEP flap reconstruction $n=11$ ) were interviewed at a median of 14 months (range 2-37 months) following surgery. Twenty-eight women had undergone reconstruction at the time of mastectomy (IBR) and eight received delayed reconstructive procedures (Table 2).

Participants' perceptions of access to care and the provision of choice. Professionals described providing comprehensive choices and full access to care to patients. This, however, was not how patients perceived that their choice of reconstruction had been delivered and some described how their choice had been limited.

'I think it's just knowing what was available from the word 'go' and the different results, the pros and cons for the different types.... don't think I was given that.' (Donna, aged 50, Immediate EIBR)

Restricted choice and access to BR was attributed to one of three main themes that emerged from both patients and professionals interviews. These were a lack of information and/or time during decision making; mismatches between patients' desired and actual involvement in the decision and issues surrounding the organisation and practicalities of the delivery of the BR service in that region. These themes often overlapped.

Lack of information and time for decision making. Some women described a lack of high-quality information about different procedure types and the probable outcomes, and how this made it difficult to make an informed decision.

'Nobody's got pictures of my one [DIEP]. All the pictures they've got are back muscles... or false [implants] an' that didn't give me any clue as to what this would look like, so that was quite annoying in that respect.' (Sandra, aged 44, Immediate-delayed DIEP BR)

A small group of women perceived that the information given to them by the surgical team was biased towards particular reconstructive options.

'Well, it [an abdominal flap] was mentioned...but when I was talking to the [Breast CNS], it was kind of like I was steered.....to the [LD-flap] ....that was not my only option, but it was the option I was being swinged towards.' (Annie, aged 46, Immediate LDBR)

Others described how they had not fully understood certain procedures and had immediately discounted them for this reason.

'I mean I didn't know what an implant entailed. So I dismissed that immediately. I just kept thinking of Jordan.' (Marie, aged 44, Immediate LDBR)

Table 1. Demographics of the 35 healthcare professionals participating in the study

\begin{tabular}{|c|c|c|c|c|}
\hline & $\begin{array}{c}\text { Breast/oncoplastic } \\
\text { surgeons, } \\
n=11(\%)\end{array}$ & $\begin{array}{c}\text { Plastic } \\
\text { surgeons, } \\
n=11(\%)\end{array}$ & $\begin{array}{l}\text { Clinical nurse } \\
\text { specialists, } \\
n=11(\%)\end{array}$ & $\begin{array}{c}\text { Clinical } \\
\text { psychologists, } \\
n=2(\%)\end{array}$ \\
\hline \multicolumn{5}{|l|}{ Gender } \\
\hline Male & 8 & 9 & 0 & 0 \\
\hline Female & 3 & 2 & 11 & 2 \\
\hline \multicolumn{5}{|c|}{ Years of consultant/CNS experience } \\
\hline$<5$ & 4 & 1 & 5 & 2 \\
\hline 6-15 years & 3 & 6 & 6 & 0 \\
\hline$>15$ years & 4 & 4 & 0 & 0 \\
\hline Median (range) & $14(0-23)^{a}$ & $13(4-29)$ & $6(1-12)$ & $1(0-1)$ \\
\hline \multicolumn{5}{|c|}{ Total number of breast reconstructions performed per year } \\
\hline$<20$ & 4 & 1 & NA & NA \\
\hline $20-15$ & 3 & 5 & & \\
\hline$>50$ & 4 & 5 & & \\
\hline Median (range) & $30(0-200)^{\mathbf{b}}$ & $40(10-290)$ & & \\
\hline \multicolumn{5}{|c|}{$\begin{array}{l}\text { Abbreviations: } \mathrm{CNS}=\text { clinical nurse specialists; } \mathrm{NA}=\text { not applicable } \\
\text { a Including one senior trainee, not yet appointed as a consultant. } \\
\mathbf{b}_{\text {Including two surgeons who did not perform breast reconstruction. }}\end{array}$} \\
\hline
\end{tabular}


Table 2. Details of the 31 patients participating in the study

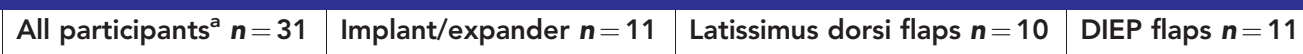

\section{Age at time of BR (years)}

\begin{tabular}{|l|c|c|c|c}
\hline Young $<45$ & 7 & 2 & 3 \\
Middle aged 45-60 & 17 & 7 & 4 \\
Older $>60$ & 7 & 2 & 3 \\
\hline Median age (years) (range) & $51.0(31-72)$ & $50.0(48-59)$ & $48.0(43-62)$ \\
\hline
\end{tabular}

\section{Marital status}

\begin{tabular}{|l|r|r|r|r|}
\hline Married & 26 & 10 & 9 \\
Divorced & 4 & 1 & 1 \\
Single & 1 & 0 & 0 \\
\hline
\end{tabular}

\section{Education}

\begin{tabular}{|c|c|c|c|c|}
\hline $\begin{array}{l}\text { Compulsory education only } \\
\text { Further education }\end{array}$ & $\begin{array}{l}16 \\
15\end{array}$ & $\begin{array}{l}3 \\
8\end{array}$ & $\begin{array}{l}8 \\
2\end{array}$ & $\begin{array}{l}5 \\
6\end{array}$ \\
\hline \multicolumn{5}{|l|}{ Employment } \\
\hline $\begin{array}{l}\text { Employed } \\
\text { Homemaker } \\
\text { Retired }\end{array}$ & $\begin{array}{r}22 \\
3 \\
6\end{array}$ & $\begin{array}{l}8 \\
1 \\
2\end{array}$ & $\begin{array}{l}7 \\
1 \\
2\end{array}$ & $\begin{array}{l}8 \\
1 \\
2\end{array}$ \\
\hline \multicolumn{5}{|l|}{ Menopausal status } \\
\hline $\begin{array}{l}\text { Premenopausal } \\
\text { Perimenopausal } \\
\text { Postmenopausal }\end{array}$ & $\begin{array}{r}16 \\
1 \\
14\end{array}$ & $\begin{array}{l}7 \\
0 \\
4\end{array}$ & $\begin{array}{l}5 \\
0 \\
5\end{array}$ & $\begin{array}{l}5 \\
1 \\
5\end{array}$ \\
\hline
\end{tabular}

\section{Timing of surgery}

\begin{tabular}{|c|c|c|c|c|}
\hline $\begin{array}{l}\text { Immediate } \\
\text { Delayed } \\
\text { Immediate/delayed }^{\mathbf{b}}\end{array}$ & $\begin{array}{r}20 \\
8 \\
4\end{array}$ & $\begin{array}{l}7 \\
1 \\
3\end{array}$ & $\begin{array}{l}8 \\
2 \\
0\end{array}$ & $\begin{array}{l}5 \\
5 \\
1\end{array}$ \\
\hline $\begin{array}{l}\text { Time since surgery (median months, } \\
\text { IQR) }\end{array}$ & $14(10-23)$ & $19(14-24)$ & $21(13-33)$ & $6(4-13)$ \\
\hline \multicolumn{5}{|l|}{ Method of detection } \\
\hline $\begin{array}{l}\text { Screen-detected } \\
\text { Symptomatic }\end{array}$ & $\begin{array}{l}13 \\
18\end{array}$ & $\begin{array}{l}4 \\
7\end{array}$ & $\begin{array}{l}4 \\
6\end{array}$ & $\begin{array}{l}5 \\
6\end{array}$ \\
\hline \multicolumn{5}{|l|}{ Pathology } \\
\hline $\begin{array}{l}\text { Invasive disease } \\
\text { DCIS }\end{array}$ & $\begin{array}{r}25 \\
6\end{array}$ & $\begin{array}{l}8 \\
3\end{array}$ & $\begin{array}{l}9 \\
1\end{array}$ & $\begin{array}{l}9 \\
2\end{array}$ \\
\hline \multicolumn{5}{|l|}{ Adjuvant therapy } \\
\hline $\begin{array}{l}\text { Chemotherapy } \\
\text { Radiotherapy } \\
\text { Hormonal therapy } \\
\text { Herceptin }\end{array}$ & $\begin{array}{r}9 \\
7 \\
21 \\
4\end{array}$ & $\begin{array}{l}2 \\
2 \\
8 \\
0\end{array}$ & $\begin{array}{l}2 \\
3 \\
6 \\
3\end{array}$ & $\begin{array}{l}6 \\
3 \\
8 \\
2\end{array}$ \\
\hline Complications & 18 & 6 & 6 & 6 \\
\hline Contralateral symmetrisation & 10 & 5 & 4 & 1 \\
\hline Revisional surgery & 10 & 3 & 5 & 2 \\
\hline
\end{tabular}

Some women expressed anger and frustration about this and reported how they had felt compelled to seek additional information for themselves.

'I think the more information you can put out there, then it's people's choice what they want to learn about. Don't just say nothing and expect them to go and do it [find information]. It's hard enough.' (Marie, aged 44, Immediate LDBR)

'I made the decision to sort of do a lot of research myself.....I don't know how anybody could have made the decision without that.' (Sue, aged 46, Immediate DIEP BR) 
In addition, several women retrospectively felt that they had based their decision on incomplete information and unrealistic expectations about the probable outcome of the reconstruction. This was particularly true of women choosing implant-based reconstructions as many had not appreciated that the result may not be as natural as they may have hoped.

'I thought it would be more of a natural look, more of a natural droop than it is.....that's what I wasn't aware of. I was never really made aware of that.' (Donna, aged 50, Immediate EIBR)

Women who chose LD reconstructions also reported how they were not prepared for the associated axillary and back morbidity.

'I don't know whether it's my fault or [the hospital's] fault that I didn't consider it all more...... I didn't appreciate that I would have tissue muscle an' fat emanating from there [the axilla] I just thought it would be in the breast.' (Nancy, aged 63, Immediate $L D B R$ )

Some described how they would have made a different decision had they been fully informed.

'If it had been impressed on me that my back would be a problem then maybe I would have said 'right we'll go for a small implant and see how it goes.' (Martha, aged 53, Immediate LDBR)

Professionals also expressed concerns that information provided by colleagues at other centres may not be balanced or equitable.

'There's one surgeon in our patch who tells patients, 'Oh, you don't want to have a DIEP, they have a fifty percent failure rate,'...... that's disinformation.' (Mr P, Plastic Surgeon, Centre 9)

Although some women felt they had been given sufficient information, they did not feel that they had enough time to consider it fully.

'I did have a lot of information but I don't know if I had a lot of time for it to sort of sink in and decide myself.' (Gloria, aged 59, Immediate EIBR)

Lack of time was identified as a major concern and many women perceived that they were being 'rushed' into making decisions about BR.

'To be told in within five minutes.....'We're going to take your breast off and hay ho..... This is how we [reconstruct] it'....it was all very, sort of, 'Oh my gosh!' (Alice, aged 53, Immediate DIEP BR)

The limited amount of time available for the decision making, particularly in the immediate setting was shared by professionals.

'Everything's gotta be done within thirty days or whatever..... it's just often one step too far and I think people are a shoehorned into making decisions quickly when in fact, you'd be far better off saying, 'Look! Hang on! As long as you get this done within two or three months, it's fine!' (Mr S, OPBS, Centre 11)

The lack of adequate patient education and in particular, insufficient information and time for decision making was perceived as effectively denying women choice.

Mismatches between patients' desired and actual involvement in decision making. Although most women felt they had shared decisions about BR with the surgical team, a minority reported being dissatisfied with the level of involvement in their care. Some women perceived that they had not been given any choice of reconstructive surgery, highlighting again poor information provision, which led them to regret their reconstructive decisions.

'I mean really he just explained what they could do for me an'.... just had to say yes or no.... Different ways weren't discussed at all....so I just went along with it 'cause I thought that was the only thing that you could have done. I did find out later that you could have the stomach muscles used etc which I probably would have gone for.....I would rather have had my own body parts rather than plastic.' (Vicky, aged 50, Immediate $L D B R$ )

Professionals also described episodes where women were effectively denied choice and 'told' what form of reconstruction they would have.

'We do have three breast surgeons in the area who just basically they tell the patients what's going to happen to them. They all just get latissmus dorsis........ There's no real choice...... there is a hammer and there is a nail and that's all there is to it.' (Mr P, Plastic Surgeon, Centre 9)

Service provision and organisation of care. The organisation of reconstructive care and the way in which this has evolved in the United Kingdom seemed to influence the provision of choice and access to care.

For example, some women initially managed at centres without any reconstructive services commented that they felt they had been dissuaded from seeking immediate reconstruction because of the additional organisation this would involve.

'[My breast surgeon] was discouraging me against having it all done in one go.....partly I think because...... it means them [breast and plastic surgeons] getting together to do it, so he to begin with, he was a little bit discouraging......but I stuck to my guns about that because I really didn't want to have to wait.' (Liz, aged 66, Immediate DIEP BR)

Furthermore, when reconstructive services were available, interviews with professionals raised concerns that the type of reconstruction that women were offered depended largely on local preferences and expertise.

'We're doing far more autologous tissue reconstructions. It's not because necessarily our patients are automatically choosing that, it's because of the educational process an' we have a particular bias, so there is a bias introduced, there's no question about that.' ( $\mathrm{Mr}$ G, Plastic Surgeon, Centre 4)

'Every unit has its own flavour....people have their own hobbyhorse techniques.' (Mr S, OPBS, Centre 11)

This was not perceived to be an issue if women were referred to centres where all forms of reconstruction were available as full choice was provided.

'We offer all aspects of reconstruction ranging from implants. ...the lat dorsi either with or without implants....various options of using tummy tissues ranging from pedicle TRAMs to the DIEP flaps...... We found that the reconstructions were fairly spread out with a slightly higher base towards autologous [options].' (Mr U, Plastic Surgeon, Centre 14)

Professionals did, however, express concerns when referrals were made to centres served by surgeons with particular preferences or a limited repertoire of reconstructive procedures. 
'I think we are short-changing women if they go to a unit in which they have a very limited repertoire..... think you have to be able to offer patients the full range because otherwise you're just short-changing them.' (Mr G, Plastic Surgeon, Centre 4)

A few patients described their frustration at being referred to a surgeon who could only perform a limited number of procedures.

'A few months later......they made me an appointment..... [with] a lady surgeon.... [who] specialised in....[reconstructions from the] back and that was the only one she offered. I didn't feel very comfortable with that......other options [were] available...... [but not] with that particular lady surgeon..... That meant $I$ had to.....get referred to somebody else and it was quite timeconsuming actually.' (Pat, 51, Delayed DIEP BR)

Some professionals were concerned that such women were not being offered appropriate choice due to the local surgeons' desire to maintain ownership of the patient and their surgery.

'I think if you have somebody who only has a limited range who is a general trainee originally...they may only have one procedure, they may only have two but ....that is what they do and they want to keep control of the patient, unless the patient actually says, 'Oh no! I want a DIEP flap.' (Mr V, Breast Surgeon, Centre 14)

There appeared to be a degree of friction between the breast and plastic surgeons with regard to the provision of reconstructive services. Some plastic surgeons perceived that the arrival of OPBS had led to them being excluded from the decision-making process to some extent.

'I taught them [breast surgeons] how to do LDs and after a very short period of time I was then cut out of the decision-making process.....it means that for the vast majority of patients, there is not a complete reconstructive option being given.' ( $\mathrm{Mr}$ P, Plastic Surgeon, Centre 9)

This raised concerns that patients may not be referred appropriately, even if this may be in the patients' best interests.

'We used to do the reconstructions until the oncoplastic breast surgeon arrived and they stopped, completely stopped...... [patients] had all been denied abdominal flaps even though several of them were very very suitable for it.' (Mr O, Plastic Surgeon, Centre 8)

Similarly, some OPBS felt that plastic surgeons were encouraging women to have free-flap procedures to maintain involvement in reconstructive care.

\footnotetext{
"Everybody has to be painted into a DIEP flap. That's the corner we have to push for because this is what we can do that breast surgeons can't'....There's a little bit of prejudice and lack of touch of reality going on. 'If you've got a hammer everything looks like a nail!' - well, I think the DIEP at the moment is the hammer and I think other very good techniques of reconstruction are being cast aside for political reasons rather than for actual practical reasons.' " (Mr H, OPBS, Centre 5)
}

Both groups voiced concerns about the skills and expertise of the other speciality to support their arguments. Some older plastic surgeons perceived that OPBS lacked the technical skills and training to provide high-quality BR.

'There's a disjoint between the training and expertise of the breast surgeons and the results that they can achieve.........
There was a time when I was training where the least competent surgeons did breast work.' (Mr P, Plastic Surgeon, Centre 9)

By contrast, OPBS perceived plastic surgeons as 'technicians' who were less interested in the diagnosis and management of breast cancer as a disease.

'They wanna [be] masters of the universe...feudal technicians that come in and do the stuff but not to actually get involved in perhaps the more difficult....diagnostic-communication side of the spectrum and it's a great shame.' (Mr S, OPBS, Centre 11)

One plastic surgeon eloquently summarised the issues surrounding the provision of care as the 'elephant in the room.'

'There was this phobia about breast surgeons and I think, to be fair, on the other side as well there is this thing about, 'We don't need plastic surgeons! We can do everything - we've got LD, we've got,implants, we got autologous $L D$ - that's it! We can do it.' That view is also engendered- so it's not one side..... The oncoplastic battle between us [plastic surgeons] and yourselves [breast surgeons].....that's the elephant in the room.' ( $\mathrm{Mr} R$, Plastic Surgeon, Centre 10)

Even when free and open choice was provided, however, both patients and professionals described how women's desire for continuity of care and reluctance to travel to distant centres effectively restricted the choice to procedures that were available locally.

'I've been looked after for five years with the same breast consultant....he wasn't a plastic surgeon so he couldn't do my DIEP an' that was really difficult because I think if....he could do all the options in a way that would have made my decision a little bit easier......it just felt....quite sort of scary going with somebody new.' (Sue, aged 46, Immediate DIEP BR)

'Oncoplastic units like this that don't have plastic surgeons on tap in the clinic are perhaps disadvantaged slightly...... [patients] tend to decide not to have that type of reconstruction even though.... [they] would be best served by an abdominal flap they don't want to travel; they don't want to go an meet someone else again.' (Mr D, OPBS, Centre 2)

The evolution of a 'hub and spoke' reconstructive service delivered by two separate specialities may therefore have resulted in inequalities in access to care and the provision of choice to women considering reconstructive surgery.

Interventions to improve choice: enhancing collaboration, communication and access to care. Both patients and professionals felt that all women should be offered a fully informed choice of reconstructive procedures and proposed a number of strategies by which this may be achieved as detailed below.

Patients emphasised on the need for balanced and unbiased information about all forms of reconstruction irrespective of whether their surgeon could perform them together with details about which procedures, if any, they were unsuitable for and why and which would potentially give the best results.

'There could be more information, even if it's leaflets you can take away... because I think... when you're in that situation, you don't necessarily know the questions to ask, so you don't ask them.' (Donna, aged 50, Immediate EIBR)

They wished to be involved in these discussions but supported to make the decision if necessary. Finally, if a free flap was a viable option, women wished to be routinely referred to a plastic surgeon for discussion of their options. 
Professionals acknowledged that interventions to improve collaboration between the specialities would be necessary to improve the patient experience and several had implemented innovative strategies to facilitate this.

The geographical separation of breast and plastic surgical units was identified as one of the main barriers to collaboration. Ideally, most professionals perceived that the best outcomes could be achieved by both specialities working together at specialist centres on the same site. Centralisation of services was therefore proposed as the ideal means of improving access to care and sharing of skills, but it was recognised that for most centres, such an intervention would not be possible within the constraints of the NHS.

'I think we just want it to be set up; good centres in different parts of the country [that] are committed to breast reconstruction where oncoplastic chaps and plastic chaps work together in one place; physically work together. They have to be in clinic, they have to be in theatre....... that is the kind of thing we need to engender.' (Mr R, Plastic Surgeon, Centre 10)

Other centres had introduced innovations that were perceived to be effective within the existing model of care. The first of these was the introduction of oncoplastic multidisciplinary meetings. These were established at two centres and were attended by both breast and plastic surgeons and CNSs. All patients considering reconstructive surgery were discussed and reconstructive options recommended.

'I strongly believe that there should be an oncoplastic MDM in the same way that there's an oncology MDM. I think we need to strengthen the breast-plastic partnership because I think we work better together rather than apart. There's no doubt that in the two years we've been doing it, we've learnt enormously from the plastic surgeons and they've learnt enormously from us and so it's been a very, very fruitful relationship and, of course, it's the patients who benefit from that because you escalate the level of knowledge and skill, amongst the whole team.' (Miss N, OPBS, Centre 7)

Joint operating lists and clinics had been introduced in other centres as another way to improve collaboration. It was felt that these facilitated access to plastic surgical services and also addressed patients' concerns regarding continuity of care, as the plastic surgeon was seen as an integral member of the team from the beginning.

'I have a very good working relationship with the guys here. I think you need to have parallel clinics, which we do and I think we need to have a lot of respect for the bits that we do - we do operations together, I would like to think that the guys there, feel that if they've got somebody who needs a reconstruction, they're gonna be best served, if it's a complex reconstruction, by coming to see me. Rather than, 'Let's just give it a shot.' you know?' (Mr T, Plastic Surgeon, Centre 12)

Several high-volume centres had specialist BR clinical nurse specialists. These individuals were perceived to have a vital role in advocating for patients. Some surgeons commented that expanding the number of BR-CNSs may enhance the provision of choice.

'The key is breast care nurses... they are the pathway, the conduit through which all patients will pass. They are in a position to offer an independent view, independent of both reconstructive and breast oncoplastic surgeons, almost as patient advocate, then I think that there would be a wider diversity of choice.' ( $M r$, Plastic Surgeon, Centre 9)

Finally, inadequate training and expertise were identified as the major concerns by all professionals and the need to standardise training for surgeons performing reconstructive surgery emerged as a key theme.
'The problem is there's a huge variability in the in the level of surgery an' the standards of surgery and the people's training [is] very variable at the moment.....it's not labelling a breast surgeon versus plastic surgeon.....but I think there should be a background standardisation of the training.' (Miss E, Plastic Surgeon, Centre 3)

Interventions to improve the training of OPBS to allow them to fully appreciate the full range of reconstructive options and which patients would benefit from referral were highlighted by a number of plastic surgeons as being beneficial, and ongoing mentorship programmes for newly qualified OPBS may help to improve levels of expertise and facilitate access to care.

'I am quite well aware that oncoplastic surgeons from the general background may well end up in [a district general hospital] with no formal plastic surgery service......they do need access to free flaps. They also need access to plastic surgery..... they need help with complications. They need someone to work alongside....when they're first appointed at thirty-five or thirty-six.....they almost needed to be buddied up for two years - plus.' ( $\mathrm{Mr} \mathrm{V}$, Breast Surgeon, Centre 14)

\section{DISCUSSION}

Women seeking BR need to make choices about the type and timing of surgery. This study investigated these issues and found that women perceive that the provision of choice is variable and often inadequate. Issues relating to insufficient patient education especially a lack of information and/or time to facilitate adequate involvement in decision making explained these observations. Surgeons recognised that the evolution of reconstructive care and the organisation of services influence how reconstructive surgery is offered in the United Kingdom and these observed organisational issues may explain inequalities and access to care. Interventions to improve collaboration between breast and plastic surgeons may improve access and facilitate better information and choice for women.

This innovative study is the first to explore patients' and professionals' perceptions of the provision of choice and access to care for women seeking reconstructive breast surgery in the United Kingdom. Although some concerns relating to inadequate patient education to facilitate choice such as insufficient time and information for decision making are well-established (Contant et al, 2000; Shakespeare and Hobby, 2001; Nissen et al, 2002; Wolf, 2004a, b; Sheehan et al, 2007), issues related to the ownership of reconstructive services are a previously unreported and unanticipated barrier to the provision of high-quality care. This study therefore provides novel insights into the provision of choice and ways in which it may be improved. The work offers a plausible explanation for many of the key findings of the NMBR Audit (Jeevan et al, 2008, 2009, 2010b, 2011), in particular the variation in the patterns of care between centres. Patient satisfaction with the provision of choice in this study compares unfavourably with that seen in the National Mastectomy and Breast Reconstruction Audit (Jeevan et al, 2011), but this may reflect the limitations of the audit methodology as questionnaires may overestimate patient satisfaction or oversimplify the complex concept of satisfaction with care (Dougall et al, 2000; Rogers et al, 2000; Rowell and Polipnick, 2008; Pollock et al, 2011). Self-report questionnaires may not be an 'appropriate or adequate representation of patients' experiences of care.' (Williams et al, 1998; Crawford and Kessel, 1999), whereas the qualitative interviews in this study generated rich data that allowed the complexity of the patients' experiences to be unveiled and unpicked (Pollock et al, 2011). 
This is a novel study highlighting previously unanticipated issues in the provision of reconstructive care, but it is possible that the professional background of the researcher as an oncoplastic surgical trainee may have influenced these findings and had an impact on the results. A number of safeguards including multiple coding, triangulation and discussion of data interpretation, however, were introduced to protect the validity of the data (Mays and Pope, 1995; Mays and Pope, 1999), and the frank nature of the responses from both patients and professionals suggests this to be unlikely. Indeed, it is possible that researcher's clinical background positively influenced the study as the respondents felt able to respond freely and honestly. It may also be argued that as patients were selected from a single centre, the results may not reflect national practice. Although we acknowledge this limitation, the study centre was a large tertiary referral centre staffed by six consultant surgeons practicing in two separate units (breast and plastic surgery) each with different approaches to the provision of choice. Furthermore, approximately a third of patients in the study were referred from at least four other peripheral centres both with and without local reconstructive capacity so the participants' experiences of choice are more likely to be representative of the provision of choice and access to care nationally. Professionals were sampled from throughout the United Kingdom and the issues identified were widespread. The lack of inclusion of patients who either declined reconstruction or who were not offered surgery, however, is a limitation as their perceptions of the provision of choice were omitted from this study. These individuals may have raised additional concerns and produced further rich data to inform changes to practice. These women may also have been very well-informed for them to feel that they were able to say 'no' to surgery, which can be extremely difficult. The sample did, however, include a number of individuals who were either not offered immediate reconstruction or actively dissuaded from it, starkly reporting their experiences relating to the provision of choice, reluctance to travel to tertiary centres or to transfer care to other surgical specialities and as such, these perspectives were included to some degree. Similarly, the study sample only included two surgeons who did not offer BR. Including additional professionals who did not offer the procedure themselves may have generated future insights into how choice was provided in these circumstances. Finally, our findings relating to the patient experience may be limited by recall bias as participants were asked to recall experiences of choice retrospectively and these may have been coloured by perceptions of the outcomes of the procedure they had selected. Women would probably remember aspects of the process that had particular salience to them, however, and their vivid descriptions of aspects of their care may reflect the importance of these issues and the long-term impact that they had had on the participants' well-being.

At present, women's experiences of BR seem to be largely determined by the centre to which they are initially referred for breast cancer diagnosis and treatment, and the resources and skills of the surgeons practicing at that centre. It may be possible to improve this by increasing collaboration between breast and plastic surgeons including the introduction of oncoplastic multidisciplinary meetingss, BR-CNS, joint clinics, lists and mentoring. Standardisation in training for all surgeons performing BR may also change attitudes and engender partnership and collaboration. On an individual level, strategies to improve patient education to empower women to better participate in the process of shared decision-making by more clearly providing information about treatment options (Coulter et al, 1999) may improve women's experiences of care (O'Connor et al, 1999). Decision support interventions have been successfully used in BR in the United States of America (Heller et al, 2008; Lee et al, 2010) and BRESDEX, a decision support intervention for use in breast cancer is currently under evaluation in the United Kingdom (Caldon et al,
2011; Sivell et al, 2012). More simplistically, changing the consultation strategy to routinely include aspects of care valued by patients such as providing more time for decision making, a clear presentation of reconstructive options and a routine offer of referral to plastic surgical services, if indicated, may be a costeffective way of improving women's experiences and access to care.

The majority of women seeking BR will be long-term breast cancer survivors and the decisions that they make about reconstructive surgery are likely to have long-lasting effects on their quality of life. It is therefore vital that women are supported to make high-quality decisions about BR. At present, however, this study suggests that many patients' experiences of care may be falling short of this ideal as a result of variation in service provision and issues relating to the ownership of reconstructive care. Pathway restructuring and service reorganisation are probably necessary to improve access to care. Interventions to improve decision making, collaboration between breast and plastic surgeons and training of all future reconstructive surgeons may also be necessary to provide women seeking BR with optimal care.

\section{ACKNOWLEDGEMENTS}

SP and JB conceived the study; SP, NM and JB designed the research study and SP and JMB wrote the research protocol. SP recruited the patients with the support of SJC and undertook the fieldwork and data analysis with the support of NM and JMB. SP wrote the first draft. All authors commented on and contributed to the final draft. JMB is the guarantor of the study. This study was funded by a One Year Surgical Research Fellowship from the Royal College of Surgeons of England (SP) and Above and Beyond, the Charitable Trustees of University Hospitals Bristol NHS Foundation Trust. NM is wholly and JMB is partially funded by the MRC ConDucT Methodology Hub.

\section{CONFLICT OF INTEREST}

The authors declare no conflict of interest.

\section{AUTHOR CONTRIBUTIONS}

SP and JMB conceived the study; SP, NM and JMB designed the research study and SP and JMB wrote the research protocol. SP recruited the patients with the support of SJC and undertook the fieldwork and data analysis with the support of NM and JMB. SP wrote the first draft. All authors commented on and contributed to the final draft. JMB is the guarantor of the study.

\section{DISCLAIMER}

Ethical Approval: Southmead Research Ethics Committee, LREC reference number 09/H0102/50.

Access to data: All authors had full access to all of the data in the study and can take responsibility for the integrity of the data and accuracy of the data analysis.

\section{REFERENCES}

Baum M (2003) Is it time for a paradigm shift in the training of breast surgeons as a sub-speciality?! The Breast 12: 159-160.

Britten N (1995) Qualitative research: qualitative interviews in medical research. BMJ 311: 251-253. 
Caldon LJM, Collins KA, Reed MW, Sivell S, Austoker J, Clements AM, Patnick J, Elwyn G, Bresdex G (2011) Clinicians' concerns about decision support interventions for patients facing breast cancer surgery options: understanding the challenge of implementing shared decision-making. Health Expect 14: 133-146.

Contant C, Van WERSCH A, Wiggers T, Wai R, Van Geel AN (2000) Motivations, satisfaction and information of immediate breast reconstruction following mastectomy. Patient Educ Couns 40: 201-208.

Coulter A, Entwistle VA, Gilbert D (1999) Sharing decisions with patients: is the information good enough? BMJ 318: 318-322.

Crawford MJ, Kessel AS (1999) Not listening to patients-the use and misuse of patient satisfaction studies. Int J Soc Psychiatry 45: 1-6.

Dougall A, Russell A, Rubin G, Ling J (2000) Rethinking patient satisfaction: patient experiences of an open access flexible sigmoidoscopy service. Soc Sci Med 50: 53-62.

Glaser B, Strauss AL (1967) The Discovery of Grounded Theory Chicago, Adeline, USA.

Heller L, Parker PA, Youssef A, Miller MJ (2008) Interactive decision aid in breast reconstruction. Plast Reconstr Surg 122: 717-724.

Jeevan R, Cromwell D, Brown J, Trivella M, Pereira J, Caddy C, Sheppard C, Van Der Meulen J (2010a) Regional variation in the use of immediate breast reconstruction after mastectomy for breast cancer in England. Eur J Surg Oncol 36: 750-755.

Jeevan R, Cromwell D, Browne J, Van Der Meulen J, Pereira J, Caddy C, Sheppard C, Greenaway K, Napper R, Dean S (2008) First Annual Report of the National Mastectomy and Breast Reconstruction Audit.

Jeevan R, Cromwell D, Browne J, Van Der Meulen J, Pereira J, Caddy C, Sheppard C, Greenaway K, Napper R, Dean S (2009) The National Mastectomy and Breast Reconstruction Audit. A national audit of provision and outcomes of mastectomy and breast reconstruction surgery for women in England. Second Annual Report..

Jeevan R, Cromwell D, Browne J, Van Der Meulen J, Pereira J, Caddy C, Sheppard C, Greenaway K, Napper R, Dean S (2010b) National Mastectomy and Breast Reconstruction Audit 2010. Third Annual Report.

Jeevan R, Cromwell D, Browne J, Van Der Meulen J, Pereira J, Caddy C, Sheppard C, Greenaway K, Napper R, Dean S (2011) National Mastectomy and Breast Reconstruction Audit 2011.

Kuper A, Reeves S, Levinson W (2008) An introduction to reading and appraising qualitative research. BMJ 337: a288.

Lee B, chen C, Yueh J, Nguyen MD, Lin S, Tobias A (2010) Computer-based learning module increases shared decision making in breast reconstruction. Ann Surg Oncol 17: 738-743.

Malterud K (2001) The art and science of clinical knowledge: evidence beyond measures and numbers. Lancet 358: 397-400.

Malycha P, Gough I, Margaritoni M, Deo S, Sandelin K, Buccimazza I, Agarwal G (2008) Oncoplastic breast surgery: a global perspective on practice, availability, and training. World J Surg 32: 2570-2577.

Mays N, Pope C (1995) Qualitative research: rigour and qualitative research. BMJ 311: 109-112.

Mays N, Pope C (1999) Quality in qualitative research. In: Mays N, Pope C (eds). Qualitative Research in Healthcare. BMJ Publishing: London, UK.

National Institute Of Clinical Excellence (2009) Breast cancer (early \& locally advanced): diagnosis and treatment.

Nissen MJ, Swenson KK, Kind EA (2002) Quality of life after postmastectomy breast reconstruction. Oncol Nurs Forum 29: 547-553.

O'Connor AM, Fiset V, Degrasse C, Graham ID, Evans W, Stacey D, Laupacis A, Tugwell P (1999) Decision aids for patients considering options

APPENDIX 1

\section{Study Topic Guides}

Patient semi-structured interview schedule for the BRAVE study investigating the feasibility of clinical trials in breast reconstruction.

\section{Introduction}

Introduce self and research question

Explain need to record interview and test tape recorder-explain need for recording

Undertake written informed consent affecting cancer outcomes: evidence of efficacy and policy implications. J Natl Cancer Inst Monogr 25: 67-80.

Pollock K, Moghaddam N, Cox K, Wilson E, Howard P (2011) Exploring patients' experience of receiving information about cancer: a comparison of interview and questionnaire methods of data collection. Health 15: 153-172.

Pope C, Mays N (1995) Reaching the parts other methods cannot reach: an introduction to qualitative methods in health and health services research. BMJ 311: 42-45.

Pope C, Ziebland S, Mays N (2000) Analysing qualitative data. BMJ 320: $114-116$.

Potter S (2011) Investigating the Feasibility of Randomised Clinical Trials in Breast Reconstruction. PhD, University of Bristol.

Potter S, Brigic A, Whiting P, Cawthorn SJ, Avery K, Donovan J, Blazeby J (2011a) Reporting clinical outcomes of breast reconstruction. A systematic review. J Natl Cancer Inst 103: 31-46.

Potter S, Cawthorn S, Mills N, Blazeby J (2013) Investigation of the feasibility of clinical trials in breast reconstruction. Lancet 381: S88.

Potter S, Harcourt D, Cawthorn SJ, Warr R, Mills N, Havercroft D, Blazeby J (2011b) Assessment of cosmesis after breast reconstruction surgery: a systematic review. Ann Surg Oncol 18: 813-823.

Rogers A, Karlsen S, Addington-Hall J (2000) 'All the services were excellent. It is when the human element comes in that things go wrong' dissatisfaction with hospital care in the last year of life. J Adv Nurs 31: 768-774.

Rowell RM, Polipnick J (2008) A pilot mixed methods study of patient satisfaction with chiropractic care for back pain. J Manipulative Physiol Ther 31: 602-610.

Shakespeare V, Hobby JH (2001) Choices and information offered to patients undergoing immediate post-mastectomy breast reconstruction: a survey of patient opinion and self-assessed outcome. Breast 10: 508-514.

Sheehan J, sherman kA, Lam T, Boyages J (2007) Association of information satisfaction, psychological distress and monitoring coping style with post-decision regret following breast reconstruction. Psychooncology 16: 342-351.

Sivell S, Marsh W, Edwards A, Manstead ASR, Clements A, Elwyn G (2012) Theory-based design and field-testing of an intervention to support women choosing surgery for breast cancer: BresDex. Patient Educ Couns 86: $179-188$.

Skillman JM, Humzah MD (2003) The future of breast surgery: a new subspecialty of oncoplastic breast surgeons? Breast 12: 161-162.

Williams B, Coyle J, Healy D (1998) The meaning of patient satisfaction: an explanation of high reported levels. Soc Sci Med 47: 1351-1359.

Wolf L (2004a) The information needs of women who have undergone breast reconstruction. Part I: decision making and sources of information. Eur J Nurs Oncol 8: 211-223.

Wolf L (2004b) The information needs of women who have undergone breast reconstruction. Part II: information giving and content of information. Eur J Oncol Nurs 8: 315-324.

This work is published under the standard license to publish agreement. After 12 months the work will become freely available and the license terms will switch to a Creative Commons AttributionNonCommercial-Share Alike 3.0 Unported License.

\section{Research questions}

1. What outcomes do patients feel are important in breast reconstruction and are useful in the decision-making process.

2. How would patients feel about being asked to participate in a randomized clinical trial investigating different types of breast reconstruction.

\section{Clarification of Details}

Although focus of interview is on your views about BR, it is helpful to get some background information about you to see if other people like you are saying similar things. 
So are you working at the moment?... Need to clarify some surgery details.

- Name and DOB (partners name if present / relevant)

- Date of surgery (month and year)

- Type and timing of surgery (Implant, LD, TRAM/DIEP)

- Additional surgery required

- Record who is present at the interview (eg patient, partner etc)

\section{Information and decision-making in breast reconstruction}

I'm interested in your thoughts on your breast reconstruction and your thoughts of a clinical trial in this area. But 1st can you talk me through the events leading up to your BR. So, when did you 1st know something was wrong? What happened then? How were you diagnosed?

- Tell me your story-how did you get to this point?

- Did you know there were other types of BR?

- Why did you decide to have the type of reconstruction you had rather than any other?

- Did everything go smoothly or were there any problems?

- Where did you get your information from? (probe what infowas it enough for their needs)

- What did you find the most useful?

- Were you shown photographs of other women? Did this affect your decision? If so how?

- Were you told about the pros and cons of surgery? Did it prepare you for the experience?

- Were you told about other women's experiences? Did you find it useful/would you have found it useful?

- Did the information you received help you to form realistic expectations of the operation?

- Is there any information that you would have found useful or wish you had been told before your operation?

- Overall, how do you feel about the results of your breast reconstruction? Probe good and bad things, anything that could be improved.

- When you were thinking about breast reconstruction - what was important to you? What did you hope to achieve? (cosmesis, rapid recovery etc.)

- Did you get out of it what you wanted?

- Would you recommend it to a friend?

\section{Participation in a clinical trial}

Are you taking part in any clinical trials? Have you ever taken part in a trial do you know what a clinical trial is? What is it and why is it done?

Explain clinical trials. Done where there are 2 treatments/ operations when the medical community as a whole doesn't know which is best. Individual surgeons may have preferences, but noone knows what's best as there hasn't been enough research.

If you agree to take part in the trial, which of the two treatments you would receive would be decided by chance - like flipping a coin. This is done so that you have two groups of similar patients that can be compared in an unbiased way (unbiased comparison).

So imagine you were discussing BR now. How would you feel if Mr X discussed two different operations with you but told you that because he was uncertain about which one was best, that he would be would be happy for the operation you received to be decided by chance/randomisation? (maybe use situation with patient's own type of reconstruction e.g. implant $v s$ implant and flap or 2 different types of flap)

How would you feel about you surgeon telling you that he or she didn't know which operation was best for you?
- How would you feel about the type of reconstruction being chosen by a computer and not actually making the decision yourself? Is there a better way?

- What things may worry you about taking part in such a study? Would you rather the surgeon suggested which operation may be right for you? Even if he didn't know which was best?

- Would you think about taking part in such a study? Explore-if yes why; if no why.

- Going back to information, what sorts of things would you like to know about before you thought about taking part?

\section{Closing Questions}

Is there anything else you'd like to tell me about Re-iterate thanks and confidentiality

Healthcare professional semi-structured interview schedule for the BRAVE study investigating the feasibility of clinical trials in breast reconstruction

Face to face interview to take place at a time convenient to the professional

\section{Introduction}

Introduce self and research question

Written consent obtained prior to interview - verbally confirm consent to interview and audio recording

\section{Research questions}

What outcomes (clinical and patient reported) should be evaluated in breast reconstruction research?

How do health professionals feel about randomized trials in breast reconstruction and what are the reasons for these feelings?

Clarification of details and background information (see proforma)

- Name and age

- Profession and specialty

- Number of years practicing/years of experience

- Types of reconstruction performed at centre

- Numbers of reconstructions performed per year

- Practice of immediate/delayed reconstruction

Decision making for breast reconstruction and participation in clinical trials

- Patient comes in with a new breast cancer that requires mastectomy. Run me through how you decide whether the patient should have reconstruction?

- If the patient wants reconstruction, run me through how you decide what types of breast reconstruction to offer to the patient?

- What outcomes are your patients told about during decision making? What do you think are important?

- What evidence is this information based on? If own data how do they monitor results - database etc?

- What types of information are patients given? (leaflets, photos, other patients etc)/ $\mathrm{PRO} /$ cosmetic/clinical

- Who is responsible for giving information?

- What do you think of the quality of the information patients are given? Are the patients satisfied?

- Do you routinely assess cosmetic outcome? If so, how, if not why? Barriers/facilitators?

- Do you assess any types of patient reported outcome? Explore why?

- Ultimately, how are decisions made about which type of BR the patient will undergo?? recommendation made by surgeon? informed patient led 


\section{Randomised trials in breast reconstruction}

- Participation of unit in clinical trials?

- Attitude to clinical trials in the unit? Are BR patients approached about participation in clinical trials? How is this done?

- How would you feel about a randomized clinical trial of types of breast reconstruction?

- Why do you think that? (explore and probe)

- If a trial was to happen - what study design (if any) would you be happy to participate in and recruit patients to?
- Are they any reasons why you wouldn't recruit patients to such a study?

- Do you think patients would take part in the study? (explore why- yes and no)

- Barriers and facilitators to recruitment

\section{Closing Questions}

Thank them for their time Any final comments they would like to make? 